psoriasis "de novo" appeared as a native origin of juvenile arthritis and CNS - multiple sclerosis. This is the first case of developing MS under the abatacept therapy among the 1118 pts (2002-2018) who receive biological therapy in our clinic.

Disclosure of Interests: None declared

DOI: 10.1136/annrheumdis-2019-eular.5320

\section{AB1006 THE CLINICAL SPECTRUM OF TWO HETEROZYGOUS MUTATIONS IN THE MVK GENE CONFIRMING HYPERIMMUNOGLOBULIN D SYNDROME}

Dragana Lazarevic ${ }^{1}$, Jelena Vojinovic ${ }^{2}{ }^{1}{ }^{C}$ linical Center Niš, Clinic of Pediatrics, Niš, Serbia; ${ }^{2}$ University of Niš, Faculty of Medicine, Niš, Serbia

Background: Autoinflammatory syndromes represent the wide spectrum of rare diseases (associated with genetic disturbances) characterized by the presence of chronic or recurrent systemic inflammation with diverse clinical presentation.

Objectives: We report a case report of child with confirmed two heterozygous mutations in the MVK gene with clinical features associated hyperimmunoglobulin D syndrome.

Results: We present girl with clinical symptoms starting just after birth when in the first days of life she was examined at gastroenterology department in Belgrade due to elevated parameters of inflammation, anemia, direct hyperbilirubinaemia, abdominal bloating and hepatosplenomegalia. Breastfeeding was discontinued due to galactosuria and lactose free diet was advised. Due to the maintenance of hepatomegaly, a detailed hematological, virusological and gastroenterological diagnostic testing was performed. Since liver biopsy has showed portal and lobular hepatitis with cholestasis without fibrosis she was on ursofalk treatment with partial response. At five months of age she started to have recurrent episodes of fever every month for few days with no associated infection, but always followed with digestive symptomatology (abdominal pain and abdominal flatulence) and elevation of inflammatory parameters. Despite antibiotics, episodes of fever continued to repeat twice monthly with accompanying occurrence of hypersalivation, small ulcers in the mouth, skin rash, cervical lymphadenopathy, hepatosplenomegaly, abdominal pain and abdominal bloating with elevated inflammatory markers. One year later she was admitted for the first time at our department and detailed differential diagnostic testing was performed. Clinical spectrum of presenting symptoms with specific phenotypic aspect (hypertelorismus and frontal bossing) were enough to suspect on autoinflammatory disease background (hyper $\lg D$ syndrome), but without $\lg G$ increase. Genetic testing have revealed presence of two heterozygous mutations ( heterozygous variant c.790del p.(Leu264Serfs ${ }^{*} 2$ ) and heterozygous variant c.1129G>A p. (Val377lle) in the mevalonate kinase deficiency gene (MVK gene) confirming hyperimmunoglobulin D syndrome. Introduction of nonsteroidal antiinflammatory drug and corticosteroids have led to complete or partial remission during a fever episodes. As fever episodes continued on every two weeks we are about to start with donated fully-humanized protein (canakinumab), highly efficacious in fever episodes resolution by blocking interleukin-1 beta cytokine.

Conclusion: Diverse clinical manifestations of some patients with autoinflammatory diseases can provoke differential diagnostic and treatment dilemmas. Genetic testing is of great importance for establishing the final diagnosis and starting accurate treatment in order to prevent potential serious complications seen in these patients.

Disclosure of Interests: None declared

DOI: 10.1136/annrheumdis-2019-eular.7899

\section{AB1007 PREVALENCE AND CHARACTERISTICS OF TEMPORO- MANDIBULAR JOINT (TMJ) INVOLVEMENT IN A COHORT OF YOUNG ADULT PATIENTS WITH DIAGNOSIS OF JUVENILE IDIOPATHIC ARTHRITIS (JIA) AND NON-JIA CHRONIC INFLAMMATORY ARTHROPATIES}

Adriano Lercara ${ }^{1}$, Gloria Crepaldi ${ }^{1}$, Francesco Licciardi ${ }^{2}$, Marco Davico ${ }^{3}$, Stefano Cirillo ${ }^{3}$, Sarah Marouen ${ }^{4}$, Enrica Vandelli ${ }^{4}$, Yves-Marie Pers ${ }^{4}$, Claudia Lomater ${ }^{1} .{ }^{1}$ Ospedale Mauriziano Umberto I, Rheumatology Unit, Turin, Italy, ${ }^{2}$ Ospedale Regina Margherita, Immuno-Rheumatology Department, Turin, Italy; ${ }^{3}$ Ospedale Mauriziano Umberto I, Radiology Unit, Turin, Italy; ${ }^{4} \mathrm{CHU}$ Lapeyronie, Rheumatology Unit, Montpellier, France

Background: TMJ is involved in about $50 \%$ of JIA cases, often bilateral and asymptomatic in up to $71 \%$ of cases $^{1}$. Adult patients with JIA have been shown to have, compared to healthy individuals, higher rate of dysfunction and anatomical abnormalities ${ }^{2}$. Clinical examination has been shown to have high specificity but low sensitivity in revealing TMJ inflam mation $^{3}$. To date $\mathrm{MRI}$ is the gold standard to assess TMJ involvement ${ }^{4}$ Objectives: To investigate the prevalence of TMJ involvement in young adults with JIA and young adults with non-JIA inflammatory rheumatisms. Methods: Patients were recruited prospectively in 2 clinical centers. Inclusion criteria were: patients $<35$ years diagnosed with JIA who had undergone transition from the pediatric to the adult rheumatologist, and patients diagnosed with non-JIA inflammatory arthropathies. All patients were assessed for joint count, clinical examination for TMJs (tenderness to palpation, swelling, signs of damage such as joint crepitations, latera deviation, retrognathia and decreased mouth opening), evaluation of globa disease activity with composite indexes and underwent MRI of the TMJs to detect inflammation (bone marrow edema, effusion, synovial thickening) or damage (condylar flattening, erosions, disk abnormalities); MRls with either inflammation or damage were considered pathological. Demographic and clinical characteristics were described using frequency or median and interquartile range $(\mathrm{IQR})$, depending on the distribution of the variable. Differences between groups were analyzed using the Mann-Whitney $U$ test and the $\chi^{2}$ test when appropriate. The significance was set at $p$ value $\leq 0.05$.

Results: 19 patients were included in the JIA group and 8 patients in the non-JIA group. Patients' demographic and disease characteristics were reported in Table 1.

\begin{tabular}{lcc}
\hline & JIA & Non-JIA \\
& $\mathrm{n} 19$ & $\mathrm{n} 8$ \\
\hline Sex F, $\mathrm{n}(\%)$ & $16(84.2 \%)$ & $4(50 \%)$ \\
Age (ys) at diagnosis, median (IQR) & $8(4-12.5)$ & $23(20.5-25.5)$ \\
Current age (ys), median (IQR) & $22.5(20.2-27.1)$ & $29.5(28.1-32.5)$ \\
Disease duration (ys), median (IQR) & $16(13-17)$ & $6(5.8-8.5)$ \\
Global disease activity, $\mathrm{n}(\%)$ & & \\
Remission & $12(63.1 \%)$ & $4(50 \%)$ \\
Low & $1(5.3 \%)$ & $2(25 \%)$ \\
Moderate & $5(26.3 \%)$ & $1(12.5 \%)$ \\
High & $1(5.3 \%)$ & $1(12.5 \%)$ \\
TMJs tenderness, $\mathrm{n}(\%)$ & $4(21.1 \%)$ & $2(25 \%)$ \\
TMJs swelling, $\mathrm{n}(\%)$ & $0(0 \%)$ & $0(0 \%)$ \\
TMJ damage, $\mathrm{n}(\%)$ & $13(68.4 \%)$ & $4(50 \%)$ \\
\hline
\end{tabular}

Abstract AB1007 Table 1

MRI results are collected in Table 2.

\begin{tabular}{lcc}
\hline & $\begin{array}{c}\text { JIA } \\
\text { TMJs n 38 }\end{array}$ & $\begin{array}{c}\text { Non-JIA } \\
\text { TMJs n 16 }\end{array}$ \\
\hline Inflammation on MRI, $\mathrm{n}(\%)$ & $14(36.8 \%)$ & $5(31.2 \%)$ \\
Joint damage on MRI, $\mathrm{n}(\%)$ & $26(68.4 \%)$ & $11(68.8 \%)$ \\
Pathological MRI, $\mathrm{n}(\%)$ & $26(68.4 \%)$ & $11(68.8 \%)$ \\
TMJ involvement, $\mathrm{n}$ patients (\%) & & \\
Monolateral & $2(10.5 \%)$ & $1(12.5 \%)$ \\
Bilateral & $12(63.2 \%)$ & $5(62.5 \%)$ \\
\hline
\end{tabular}

Abstract AB1007 Table 2

There are no statistically significant differences between groups for the presence of inflammation on MRI, while damage (in particular, disk abnormalities) is more likely in JIA rather than non-JIA patients $(p=0.02)$. Joint effusion is more likely to be mild rather than moderate/severe in JIA patients $(p=0.04)$

Conclusion: It was found that it is more likely to find damage on MRI in patients of both groups rather than inflammation. Both groups show the same frequency of TMJ involvement, suggesting that TMJ involvement must be sought by the adult rheumatologist as it not only affects JIA patients, but also those with adult-onset inflammatory arthropathies.

\section{REFERENCES}

[1] Billiau AD, et al. J Rheumatol. 2007 Sep;34(9):1925-33

[2] Arvidsson LZ, et al. Radiology 2010 Jul;256(1):191-200

[3] Koos B, et al. J Rheumatol. 2014 Sep;41(9):1871-7

[4] Hemke R, et al. Eur Radiol. 2014 Feb;24(2):327-34.

Disclosure of Interests: None declared

DOI: 10.1136/annrheumdis-2019-eular.3050 